\title{
La obediencia civil durante la Alemania nacionalsocialista (1933-1945): condiciones para comprender un fenómeno social complejo
}

Civil obedience in national socialist Germany (1933-1945): conditions to understand a complex social phenomenon

\author{
Ariel Alvéstegui \\ iugetsevla@gmail.com \\ Universidad de Chile \\ Chile
}

\section{Resumen}

En el presente artículo se da cuenta de los resultados de un estudio cualitativo acerca de las diferentes condiciones que permiten comprender la obediencia civil en regímenes dictatoriales, y específicamente acerca de cómo se puede entender este fenómeno durante la Alemania nacionalsocialista. Esta problemática ha rondado constantemente el debate sociológico y filosófico del siglo XX acerca del Holocausto. Aquí se busca responder esta pregunta a través del rescate de la memoria y de la experiencia de los inmigrantes judíos-alemanes que vivieron el nazismo en Alemania (1933-1945), y arrancando de él llegaron a Chile. Se da cuenta de la obediencia civil como un fenómeno social complejo, dentro del cual se pueden rastrear una serie condiciones contextuales, intervinientes, causales e interacciones para comprender el acuerdo público y privado frente al régimen dictatorial.

Palabras Claves: Obediencia- Memoria- Inmigrantes judíos- Holocausto- Regímenes dictatoriales 


\begin{abstract}
The present article summarizes the results of a qualitative study aimed at understanding the conditions leading to civil obedience within dictatorial regimes and particularly during National Socialism in Germany. Civil obedience under dictatorial regimes has been an important issue discussed both in the philosophical and sociological literature on the Holocaust during the 20th Century. We address the question through the memory and experience of a number of GermanJewish immigrants who experienced Nazism in Germany (1933-1945), and escaped to Chile. In this study we conclude that civil obedience is a complex social phenomenon that arises from a number of historical and social interactions and conditions that allow us to understand the public and private acceptance of a dictatorial regime.
\end{abstract}

Keywords: Obedience-Memory-Jewish immigrants-Holocaust- Dictatorial regimes.

Agradecimientos a Lore Heppner, Grete Schmitz, Margot Lewy, Ursula Michels y Eva Rogazinski.

En memoria de Rudy Hirsch, quien con paciencia me contó tanto de su vida y de su experiencia. A todos aquellos que hicieron y hacen lo (im) posible para resistir en los tiempos que todo parece perdido.

\title{
Introducción y problematización: ¿Por qué estudiar esto hoy?
}

"Terror es la situación que empujó a los alemanes a ignorar la existencia de Auschwitz, a muchos chilenos a no aceptar saber de los detenidos desparecidos, de las torturas masivas. Se trataba de una complicidad silenciosa, que permite la adopción generalizada de la crueldad como un medio legitimo para obtener 
grandes fines, la transformación de Chile en una gran nación, en el Chile actual”. (Moulian, 1997, pp. 28-29)

En este breve ensayo presenta los resultados de una investigación cualitativa realizada el año 2014 que pretende comprender sociológicamente las condiciones que permitieron la obediencia civil durante el periodo de la Alemania nazista (1933-1945). Se trata de una problemática histórica pero actual, en tanto se plantea a modo de rescate de una memoria relevante para analizar fenómenos más cercanos, como la obediencia en las dictaduras cívico-militares latinoamericanas. Si bien en el caso chileno se trató de una dictadura autoritaria con un grado de intromisión menor en todos los aspectos de la vida social que durante el régimen nazi, existen prácticas comunes como la persecución de grupos ideológicos específicos, la abolición de los partidos políticos, los toques de queda o las quemas de libros, que permiten trazar similitudes entre ambos períodos (Moulian, 1997).

Dentro del campo de la historia y las ciencias sociales se ha investigado ampliamente el tema de los regímenes dictatoriales vistos en sus facetas autoritarias y totalitarias. Los estudios que realizó Ernst Cassirer en el ámbito de la filosofía, así como Hannah Arendt en Los orígenes del totalitarismo (1951), los trabajos de Adorno y Horkheimer en la Escuela de Frankfurt, así como la teoría de René Girard (1982) acerca del pueblo judío como tipo ideal de "Chivo expiatorio" en diferentes momentos de la historia antigua y moderna son ejemplos de aquello. Asimismo existen numerosos archivos acerca de las condiciones sociales, políticas y económicas que precedieron el ascenso del nazismo, entre otros, los archivos de los distintos Museos Judíos, las colecciones que tiene el Center for Jewish History, la colección Guggenheim o los archivos del Centro de Estudios Judaicos Günther Böhm.

Una pregunta que ha rondado constantemente dentro del debate acerca de la Alemania nazi es lo que en la Escuela de Frankfurt denominaron la caída en la barbarie: ¿Cómo fue posible que sucediese el Holocausto y cómo se llegó a tal límite? 
Aquí se propuso un estudio que tomando en consideración los aportes de las investigaciones y las fuentes anteriores pudiese indagar específicamente en el problema de la obediencia civil: lo que Arendt (1963) denominó la "banalidad del mal” o lo que Adorno (1969) tematizó como “aceptación pasiva" (Mitläufertum), pero volviendo a las fuentes directas, es decir, a quienes vivieron y fueron parte de aquella historia. Sin pretender dar una respuesta definitiva a aquella problemática, nos proponemos abordar la obediencia civil en momentos en que se vulneran momentos los derechos civiles fundamentales de la población, desde una perspectiva práctico investigativa, es decir, que a través de la memoria de una generación que vivió esta experiencia se pueda llegar a comprender las condiciones sociales que la hicieron posible. Esta generación por su edad- hoy está a punto de desaparecer, se trata de los inmigrantes judío-alemanes que vivieron su infancia o juventud en los inicios del nazismo y que escapando llegaron a Chile (entre los años 1933 y $1950^{1}$ ), en parte por casualidad y en parte debido a la apertura que dio en su momento el Presidente Aguirre Cerda a los asilados proveniente de la Europa en guerra.

Todo esto hace relevante el problema de la obediencia y del acatamiento del orden durante regímenes dictatoriales (y post-dictatoriales) como un tema que debe ser analizado por las ciencias sociales, y que siguiendo a Adorno (1969) es importante analizar como una problemática propiamente ilustrada, para que centros de exterminación como Auschwitz, o en el caso de Chile los centros de desaparición y tortura como Villa Grimaldi o Tres Álamos, no se vuelvan a repetir.

Aquí la memoria juega un papel fundamental contra lo que Ernst Cassirer denominó el regreso del mito en las contradicciones y conflictos que han marcado el siglo XX. Se trata del mito totalizante que busca manipular -impregnado en la razón y la técnica- y que pone las categorías universalizantes como el Volk, la raza o el Estado por sobre cualquier pluralidad. (Arriola, 2013)

\footnotetext{
${ }^{1}$ Se tomó el periodo mencionado debido a que en 1933 el Partido nacionalsocialista (NSDAP) llega al poder tras el nombramiento de Hitler como Canciller, y el año 1950 como una aproximación a la fecha hasta la que pudieron haber llegado inmigrantes judíos-alemanes a Chile, debido a que muchos pasaron por otros países anteriormente y no llegaron directamente desde Alemania.
} 
Lo que lleva al interés por este periodo es entonces la pregunta acerca de cómo fue posible que se mantuviese este régimen nazista violando todos los derechos de una parte de la población (judíos, homosexuales, gitanos, izquierdistas, entre otros) sin mayores insumisiones o desacatos por la población en su conjunto. Esto no implica negar que en aquellos años hayan surgido movimientos de resistencia o de oposición al nazismo, ya que existen numerosos testimonios y archivos (ver estudios históricos de Deutlev Peukert) que demuestran que hubo oposición organizada por parte de los partidos de izquierda (KPD y SPD), o por grupos de civiles (Rote Kapelle o la Rosa blanca), así como actos espontáneos de disidencia, como la protesta de Rosenstrasse. Sin embargo es ineludible constatar que aquello fue una excepción, y que la norma en la Alemania nazi fue el acatamiento del nuevo orden establecido y la obediencia civil por parte de la mayoría de la población.

\section{Marco Conceptual: ¿Qué entendemos por obediencia civil?}

Para adentrarnos en el presente estudio es preciso comenzar a definir en primer lugar lo que entenderemos por obediencia civil, para ello seguimos parcialmente la definición de obediencia John M. Levine y Mark A. Pavelchak, quienes entienden que: "existe obediencia cuando un individuo modifica su comportamiento a fin de someterse a las órdenes directas de una autoridad legítima” (Levine \& Pavelchak, 1988, p.43). La diferencia que aquí haremos a esta definición es que entenderemos la obediencia civil no solamente como un fenómeno individual sino que como un tipo de acción social complejo (que no corresponde a un tipo ideal puro), que no tiene necesaria relación con la legitimidad de la autoridad sino con la dominación, en el sentido que le da Weber como: "probabilidad de encontrar obediencia a un mandato de determinado contenido entre personas dadas”. (Weber, 2005, p.43)

Hacemos este cambio conceptual debido a que consideramos que la obediencia civil es una forma de influencia social que no necesariamente se relaciona con la legalidad o la legitimidad de la autoridad, y que como plantean Levine y Pavelchak (1988), a su vez se relaciona profundamente con la conformidad al grupo. 
De acuerdo a lo anterior, entenderemos la obediencia civil como un fenómeno social complejo que dice relación con la modificación del comportamiento o actitud individual a fin de someterse a una autoridad o grupo dominante, dentro del cual denominaremos a) conformidad social al acuerdo público, a la modificación observable del comportamiento en función de la presión directa del grupo o autoridad; mientras que denominaremos como b) convencimiento ideológico al acuerdo privado, que se da fundamentalmente en un plano de la subjetividad y no requiere de la coerción constante del grupo o la autoridad para su aceptación.

\section{Diseño de investigación: ¿Cómo se realizó la investigación?}

Esta investigación fue realizada durante el año 2014, en el marco de un Taller de investigación de la carrera de sociología. En su mayor parte esta investigación utilizó el análisis cualitativo de entrevistas en profundidad como fuente directa para adentrarse en las experiencias de los actores que vivieron el ascenso del nazismo (Ruiz, 2009), así como fuentes escritas no-directas (testimonios y biografías) y datos cuantitativos.

Para abordar la obediencia civil se decidió trabajar en torno a la división propuesta por Flores y Araujo (2013) como codificación axial dentro de la teoría fundada; esta división permite agrupar ciertas categorías emergentes en el discurso de los entrevistados y ordenarlas en torno a los siguientes ejes: a) Condiciones causales, b) Condiciones intervinientes, c) Condiciones contextuales, y d) Las acciones/interacciones.

La elección del sujeto de investigación no ha sido aleatoria, sino más bien intencionada en escoger a personas que fueron perseguidas durante el régimen nazi, en este caso de judíosalemanes. La generación que se entrevistó, debido a su avanzada edad, está desapareciendo, pues ya han pasado 83 años desde el ascenso del nacionalsocialismo en Alemania. Esta generación por desgracia ha mantenido sus testimonios dentro de un círculo familiar y social muy reducido, o simplemente no ha contado su experiencia por lo traumático que resultó para sus vidas. Es así que este trabajo tiene la intención de poder rescatar este punto de vista, esta memoria, que puede significar un aporte a la sociedad tanto en términos de aprendizaje ante la amenaza de períodos 
dictatoriales, como en torno a la indagación de la "cultura del miedo" (O'Donnell, 1982), que puede subsistir aun habiendo terminado la fase propiamente dictatorial.

No se han recopilado testimonios de adherentes al régimen, en primer lugar, por el peso que tendría la contra identificación y deseabilidad social en el caso de basarse en testimonios de adherentes al régimen ${ }^{2}$. En segundo lugar, debido al interés de comprender la obediencia como una práctica social cuyos límites rebasan con mucho el período del Holocausto, así como a sus victimarios y cómplices directos ${ }^{3}$.

La importancia de la comprensión sociológica de la obediencia civil radica precisamente en poder analizar los alcances de las prácticas involucradas, activa o pasivamente en el genocidio, en la reconfiguración de las relaciones sociales que permiten la continuidad de la abulia frente al destino del otro. Por tanto el sentido subyacente a toda la investigación tiene relación con el rescate de la memoria activa -que no petrifique la barbarie en un momento y lugar dejado atrás-, una memoria en función del presente y del futuro, en la importancia que debe tener el aprendizaje y la razón en el control del pensamiento totalitario (Arriola, 2013).

En síntesis, este estudio se propuso indagar en las experiencias de vida de los inmigrantes judíos-alemanes llegados a Chile en el periodo 1933-1950 para investigar exploratoriamente: ¿Cuáles son las condiciones que permiten comprender la obediencia civil en el periodo dictatorial tras el ascenso del nazismo en Alemania?

\footnotetext{
2 "Pero tiene miedo de cualquier persona que te habla, que lo que ha hecho durante de la guerra, que es lo que ha hecho durante los días tan malos. Nadie había sido nazi, nadie, nadie, nadie. Y yo fui a la casa de esta familia, y después me dijo alguien, sabes que el esposo de la hija fue un nazi muy grande, y a mí me dijo jamás en su vida había visto un judío, no sé, ya no conocían a los judíos, eran antisemitas igual, ya no había judíos que conocer". (Entrevista 4, 2014)

${ }^{3} \mathrm{Al}$ respecto el libro de Daniel Feierstein: El genocidio como práctica social. Entre el nazismo y la experiencia argentina, Buenos Aires, FCE, 2011, que entre otras cosas critica a Daniel Goldhagen (Los verdugos voluntarios de Hitler. Los alemanes corrientes y el Holocausto, Madrid, Taurus, 1998) la construcción de una memoria sedante por medio de la ajenización y patologización del genocidio nazi, al verlo como una excepción en la historia moderna, y más aún en la historia alemana. En palabras de Feierstein: "La memoria, por lo tanto, se ajeniza en tanto no tiene que ver con nosotros, sino apenas con las víctimas y los perpetradores directos. Se trata de víctimas dignas de una compasión abstracta, perpetradores que merecen un odio y extrañeza también abstracta" (Feierstein, 2011, p.148)
} 


\section{Factores y condiciones que posibilitaron la obediencia civil: ¿Qué pudimos encontrar?}

\section{Condiciones textuales:}

"Y la gente no tenía plata, no tenía para comer, no tenía vivienda, no tenía trabajo, era un desastre total, la gente venía de la guerra y... pero yo expliqué eso en la República de Weimar, porque yo justamente como tú dices encuentro muy importante esa introducción, en ese sentido, para entender después como tú dices, ese fenómeno: como pudo una persona como Hitler, llegar al poder" (Entrevista $1,2014)$

A partir del análisis de las entrevistas se hallaron una serie de procesos y acontecimientos que permiten acercarnos a la comprensión del contexto (Araujo \& Flores, 2013) en que surgió el régimen nazi y de qué manera la obediencia civil fue lo que primó en él. En primer lugar, uno de los elementos contextuales de gran importancia es el proceso que vive Alemania después de la Primera Guerra Mundial, cuando los vencedores le imponen una serie de condiciones económicas y políticas que sumieron al país en una gran crisis económica:

"Sí, yo le doy la culpa a eso, esas injusticias que se cometieron después de la guerra, imponiendo esas condiciones tan duras en el pueblo alemán, aun si el emperador alemán había empezado la guerra, pero nada que ver, existe el pobre pueblo, que primero lo matan ahí los soldados, después vuelven, no tienen casa. Nadie ha reconocido nunca el sacrificio que han hecho como soldados, tampoco no es cierto, han peleado por su país, vuelven a su país, no tienen ni trabajo, no 
tienen ni comida y entonces viene un Hitler que dice "pero ustedes son gente grande”, y esa paz nos han tratado muy mal, der Schandfrieden von Verdún, la paz de vergüenza de Verdún, donde se firmó. ” (Entrevista 1, 2014)

En la cita anterior se ve retratado el contexto de crisis social y económica en el que está sumida Alemania tras la primera Guerra Mundial. Esto estimula el afloramiento de líderes demagógicos, y la creación de movimientos nacionalistas como el NSDAP en 1920. Luego, el periodo previo al ascenso del nazismo en 1933 estaba además marcado por altas tasas de desempleo tras la crisis de 1929, que llegaron a ser de 43,8\% de la población activa en 1932 (Galenson \& Zellner, 1957). Es en este contexto que surge el nazismo con tanta fuerza y apoyo en la población alemana, pues los nazis prometían un cambio radical en la forma de organizar la sociedad y el Estado. Es relevante comprender aquí el fenómeno del nazismo no como una dinámica aislada dentro del sistema capitalista mundial, sino como una reacción de las elites contra el avance del comunismo $^{4}$ :

"El miedo que tenían las clases altas en Alemania del comunismo, ¿no? Porque cuando terminó la guerra en 1918, entonces ahí empezó Lenin con el comunismo en Rusia (...) Y entonces la lucha por el poder de Alemania, y Hitler salió elegido el año 1933, con el beneplácito de los militares y de los aristócratas." (Entrevista $1,2014)$

Si bien los nazis se declaraban como contrarios tanto ante el comunismo como ante el capitalismo, lo cierto es que en la práctica se puede entender la economía del régimen nazi como capitalista y el régimen político como una defensa férrea de la propiedad privada (por supuesto

\footnotetext{
${ }^{4}$ Esto no apoya en ningún caso la tesis de Ernst Nolte (1994), quien justifica y desdibuja las causalidades propias del nazismo, al tratarlo como una reacción defensiva de la Europa "civilizada" ante el avance del bolchevismo "bárbaro" en Rusia. (Feierstein, 2011) 
con el sesgo racial $)^{5}$. Fueron grandes capitalistas y la elite alemana los que financiaron el partido NSDAP y también en gran parte los que se vieron beneficiados con la expropiación de las propiedades de los judíos y la desarticulación de los sindicatos de trabajadores o de cualquier forma de presión laboral.

Lo anterior explica en buena medida la indiferencia de las democracias occidentales ante lo que estaba sucediendo en Alemania, pues se veía a Hitler como el principal aliado frente al avance del comunismo soviético. Por otro lado se ha tendido a estereotipar el antisemitismo como una característica exclusiva de la Alemania nazi, sin embargo el antisemitismo estaba muy arraigado tanto antes de la llegada de Hitler al poder en Alemania ${ }^{6}$, como en los demás países occidentales, los cuales no solo cerraron sus fronteras a los inmigrantes que escapaban del nazismo ${ }^{7}$ sino que llegaron a cometer atrocidades aún mayores:

"Como te dije, que una amiga mía, que se fue ilegal, quiere decir que se fueron escondidos en los barcos, los cabros jóvenes deben tener más o menos mi edad. Los ingleses hundieron el barco, como dos barcos, en Haifa, terrible, y un hermano, el otro hermano lo llevaron a campo de concentración y no lo encontraron." (Entrevista 3, 2014)

Otro de los aspectos del contexto relevantes a considerar es el cambio que se produce en la sociedad alemana, desde una situación social de unidad nacional - por ejemplo en torno a la idea de la patria, por la que pelearon tanto judíos-alemanes como alemanes- hacia una situación de

\footnotetext{
5 "Esta ha sido y es la prótesis que necesita el mercado en ciertas situaciones de dominación amenazada. Representa a menor escala el tenebroso renacer de Auschwitz, la barbarie presentada como defensa de la lógica moderna del capitalismo y como defensa de la civilización”. (Moulian, 1997, pp. 346)

6 "Los judios no podían trabajar en cualquier cosa, antes (del nazismo) tampoco, había ciertas cosas que podían hacer y otras que no. Era más bien por tradición, también muchas universidades tenían numerus clausus, si hay 100 estudiantes, solamente cierto número, números clausus, pueden ser judios”. (Entrevista 4, 2014)

7 "Por ejemplo la gente que en esa época fue a Palestina, que Palestina en esa época era bajo el mando de los británicos, no los dejaron desembarcar, los mandaron de vuelta a Alemania, y de vuelta a Alemania significa ir a los campos de concentración, más bien a los campos de exterminio”. (Entrevista 1, 2014)
} 
quiebre social radical. La exclusión de los judíos se hace patente ya con las Leyes de Núremberg, pero principalmente tras la Noche de los cristales rotos, el 9 de noviembre de 1938, en donde la identidad alemana excluye a lo judío. Aquí se resalta el paso de aquello que Feierstein (2011) conceptualiza como construcción de otredad negativa -y que Larraín (2001) cataloga como identidad por oposición- hacia una fase de hostigamiento, donde lo identitario judío se ve modificado: "Nosotros éramos alemanes, lógico que éramos alemanes, pero era muy claro que éramos judios, era bastante claro si...”. (Entrevista 1, 2014)

\section{Condiciones intervinientes:}

"Totalitarismo difiere esencialmente de otras formas de opresión política que nos son conocidas, como el despotismo, la tiranía y la dictadura. Allí donde se alzó con el poder desarrolló instituciones políticas enteramente nuevas y destruyó todas las tradiciones sociales, legales y políticas del país.” (Arendt, 1998, p. 396)

A partir del análisis de las entrevistas en profundidad se identificaron además una serie de condiciones que alteraban y/o modificaban el impacto de las causas sobre el fenómeno de la obediencia civil (Araujo \& Flores, 2013). En primer lugar es preciso considerar la población que fue perseguida durante el nazismo fueron tanto judíos como gitanos, homosexuales, negros, enfermos mentales, comunistas y opositores políticos. Sin embargo, si consideramos que el foco de las leyes discriminatorias estaba dirigido hacia los judíos, salta a la vista de inmediato un detalle, esto es lo reducida que era la población judía en Alemania, tanto en términos absolutos como en términos relativos si se le compara con la población judía en países de Europa oriental. ${ }^{8}$ Esto llama la atención, ya que a primera vista no se entiende por qué se enfatiza tanto la discriminación a un grupo que es tan minoritario en Alemania. Se llega a entender sólo inicialmente dentro de los esfuerzos del Estado totalitario por la búsqueda de lo que Girard (1982) denominó un chivo expiatorio:

\footnotetext{
${ }^{8}$ La población judía en 1933 en Alemania era de tan solo 565.000 - concentrados principalmente en las grandes ciudades- en relación al total de 67 millones de habitantes (sólo un 0,75\%); mientras que en los países de Europa oriental la población era muy superior: en Polonia esta cifra alcanzaba los 3 millones y en Rumania casi 900 mil. (United States Holocaust Memorial Museum, 2014)
} 
“Don't go back to Germany, no vuelvas a Alemania, porque le va a ir muy mal a Alemania, van a tener que pagar una indemnización muy grande y el país va a sufrir económicamente y cuando ya no saben qué hacer los de arriba, culpan a los judios y todo eso". (Entrevista 4, 2014)

Sin embargo, aquella aproximación únicamente describe el movimiento de exclusión, pero no llega a comprender por qué que el régimen nazi dirigiera su aparato de exterminio hacia los judíos ${ }^{9}$. Sin ser este un trabajo centrado en aquel debate, se considera significativa la propuesta de Feierstein (2011), que destaca el lugar que ocupaba el judío -y otros perseguidos- dentro de las relaciones sociales que el nazismo pretendía destruir material y simbólicamente. En primer lugar se trataba de un sujeto social distante de la normalización estatal y de la identidad occidental hegemónica, de ahí lo que vimos en relación a la ubicuidad del antisemitismo europeo, comparable a la fobia occidental actual hacia el mundo islámico. En segundo lugar compartía características de autonomía (cultural, política, religiosa) con los disidentes políticos, homosexuales, gitanos, y otros grupos perseguidos. No se trata entonces de víctimas perseguidas delirantemente por "ser" judías, homosexuales o disidentes, sino por la amenaza que su hacer constituía para la construcción totalizante de la nación que el nazismo pretendía instalar.

Dentro de este marco se logra captar la atención del régimen por la estigmatización ${ }^{10}$ y estereotipación de la población perseguida, y especialmente de la población judía a través del aparato ideológico del Estado alemán, que a la vez promovía una exaltación de la identidad alemana en oposición a la del perseguido, por ejemplo en el culto al físico ario. En esto los medios de comunicación y propaganda, que instaban al odio y a la xenofobia, fueron condición sin la cual no habría sido aceptable o siquiera pensable el exterminio:

\footnotetext{
${ }^{9}$ Feierstein (2011) examina y contrapone las posturas de Arno Mayer y Christopher Browning, donde el primero se centra en el carácter político-funcional de la persecución de los judíos, mientras el segundo lo hace en el aspecto ideológico-racial. Feierstein por su parte plantea una mirada acerca de sujetos y prácticas sociales, que deja de pensar en la lógica de "víctimas inocentes" y "victimarios demoniacos", en el sentido que ello pueda justificar la idea de que pudieran existir "victimas culpables" de genocidio, o construcciones de los victimarios como asociales.

${ }^{10} \mathrm{La}$ intención de estigmatizar a los judíos se ve reflejada claramente en medidas tales como la obligación de tener una estrella de David en la ropa o en los pasaportes, donde se anteponía el nombre Sara o Moisés según el sexo.
} 
"Der Sturmer! It was the name of this diary (...) Así, un diario, si tú dices propaganda es gentil la expresión porque es de odio, de fomentar odio, de lo que hacen los judíos y los judios que matan niños chicos y se toman la sangre de los niños chicos, tienen esas miles de cosas así, pero cosas horribles, imposibles de imaginar. Y todo eso lo ponen en ese tipo de panfleto, digamos, para no decir, porque se llaman diarios, pero son como panfletos y son para fomentar el odio. To pave the way you see, to watch the Endlösung, ellos te alistan el camino para "la solución final”, que quiere decir la muerte, la matanza, el asesinato de la gente. Como si yo haría un panfleto así todos los días contra los gitanos y después los llevo y los asesino. Eso lo han hecho, lo han hecho con los gitanos igual." (Entrevista 1, 2014)

El Estado totalitario tenía su expresión prácticamente en todos los aspectos de la vida, llegaba a controlar el presente y el futuro de las personas a través del Terror ${ }^{11}$. Por último, una de las condiciones que más destacaba en las entrevistas realizadas fue la imposibilidad de imaginar el quiebre radical en la sociedad y el Holocausto:

"Y mi mamá decía esto: Ach so, das ist doch die Spanische Krieg! Eso es la guerra española, esas cosas, hier passiert so was nicht, aquí esas cosas no pasan. Y después mira lo que pasó, que fue mil veces peor de lo que pasó en España. Ese

\footnotetext{
${ }^{11}$ Terror, que en palabras del sociólogo chileno Tomas Moulian, refiere a: "la capacidad que tiene un Estado de actuar sobre los cuerpos de los ciudadanos sin tener que reconocer en la intensidad de las intervenciones o de los daños y sin tener que enfrentar efectivas regulaciones en la determinación de los castigos o prohibiciones. Terror es la capacidad absoluta y arbitraria de un Estado de inventar, crear y aplicar penas o castigos sin más limites que las finalidades que se han definido. Terror es la capacidad de un Estado para conseguir el acuerdo de muchos ciudadanos que se autoconciben como pacíficos y tolerantes, para usar violencias y daños contra enemigos políticos, en nombre de un bien mayor". (Moulian, 1997, p. 28)
} 
era el punto que yo te iba a decir, nadie se imaginaba una cosa de esa envergadura, esa es la verdad." (Entrevista 1, 2014)

Para todos era simplemente inconcebible el extremo al cual se llegó, especialmente inconcebible por su concepción de Alemania como un país de cultura civilizada:

“Muy pocos pudieron salir, porque nadie creyó que pudo pasar lo que paso, en Alemania, no, tal vez en Polonia, en Rusia, pero Alemania no. Alguien me dijo su papa tampoco quería salir de Alemania, él decía ya va a terminar, ya va a terminar,... terminaron primero los judíos y después termino el tercer Reich. (...) Porque creían que era un país que tenía más cultura como los otros." (Entrevista 4, 2014)

\section{Condiciones causales}

"Porque no había resistencia ninguna, yo sé que ni Hitler se esperaba que iba a ser tan fácil exterminar a los judíos, porque nadie se atrevía a hacer algo, era tan fuerte, castigaban terriblemente a la gente que hacia algo contra ellos. Miedo, nadie dijo, nada, ¿y los aliados que dijeron? Nada, Churchill y no se quien, mientras no nos toca a nosotros mala suerte de los judios” (Entrevista 4, 2014)

En primer lugar, para entrar a comprender las condiciones causales de la obediencia civil en el régimen nazi es preciso la capacidad de distinción, distinguir a partir del quiebre social en la sociedad alemana, que separó y jerarquizó a la población entre aquellos que eran parte de la comunidad y aquellos que no.

En el caso de aquellos que participaron del régimen de manera activa -siendo parte como perseguidores-, la obediencia se explica como acuerdo ideológico con el nazismo. Es lo que conceptualmente definimos como convencimiento o acuerdo privado: "No cabe ninguna duda 
que la mayoría de la gente estaba con Hitler porque le dieron su voto y lo hicieron primer ministro y estaban muy entusiasmados de él, les prometió muchas cosas y votaron por él." (Entrevista 1, 2014). Es un acuerdo que no necesita de la coerción o de la presión de la autoridad. Un indicador cuantitativo acerca de la magnitud del convencimiento ideológico se puede hacer a partir del número de miembros del partido nazi, que pasó de tener 55.287 afiliados el año 1923, a 849 mil el año 1933 y una cifra cercana a los 8 millones de miembros hacia el final de la Segunda Guerra. (Historia virtual del holocausto, 2014)

Para ahondar en los motivos que estuvieron tras este apoyo parece relevante considerar el arraigo que tuvo la ideología nazi, que si bien era bastante fragmentada e incoherente (Borja, 2014), le daba una centralidad al pueblo alemán: "Él les hacía creer que Alemania va a ser muy grande, que el Heute gehort uns deutschland und morgen die ganze welt" ${ }^{, \prime 2}$, se volvieron locos con la idea de dominar todo el mundo" (Entrevista 4, 2014). Además el discurso era tremendamente demagógico ante las masas y en las políticas, en tanto proponía un futuro distinto dentro de un contexto de crisis:

"Habia mucho unemployement, cesantía, y el empezó a construir las famosas Autobahn, e inventó el Volkswagen, la gente pagaba poquito y tenía su auto, y para eso había que construir carreteras y terminó el unemployement, la cesantía y por eso mucha gente le creía, y nadie sabía lo malo que era. Después los alemanes también sufrieron mucho la guerra." (Entrevista 4, 2014)

Por otro lado, un fenómeno que se puede diferenciar teóricamente del convencimiento, pero que en la práctica estaba también a la base de la obediencia civil, es el oportunismo y el beneficio social y económico que significaba apoyar al régimen dentro del proceso de arianización:

\footnotetext{
12 Traducción propia: "hoy nos pertenece Alemania, mañana el mundo entero". 
"Ellos estaban muy contentos, este régimen les dio trabajo, les dio las casas de los judíos, muchos de ellos tenían beneficios de eso, también beneficios monetarios porque también tomaban los empleos de los que tenían vacantes, echaron a los judios y contrataron arios. Había un proceso de arianización, eso es, eliminar a los judios de sus puestos y reemplazarlos por personas no- judías." (Entrevista 1, 2014).

Lo anterior se conecta directamente con la otra dimensión de la obediencia civil caracterizada en el marco conceptual, y hace referencia a lo que denominamos conformidad social, al acuerdo público, es lo que Adorno caracteriza como interés egoísta e indiferencia por el otro y que nos acerca a la intromisión del totalitarismo en todos los aspectos de la vida, incluso una vez acabada la dictadura:

"Primariamente interés egoista: defender el provecho propio antes que nada, y, para no correr riesgos - jeso no!-, cerrar la boca. Es esta una ley general en relación con el orden establecido. El silencio bajo el terror fue solamente su consecuencia. La frialdad de la mónada social, del competidor aislado, en tanto indiferencia frente al destino de los demás, fue precondición de que solo unos pocos se movieran." (Adorno, 1969, pp. 80 a 95)

Siguiendo con el análisis acerca de la conformidad, en las entrevistas se puede observar que este fenómeno social está ligado no solo a la frialdad como propone Adorno, sino también al fenómeno psicológico del miedo. Esto especialmente si consideramos aquí a la población que no estaba de acuerdo con el régimen ni sus medidas, pero que se veía paralizada por el miedo y terminaba por tolerarlo: 
“Lógico, por lo menos lo demostraban (el acuerdo con el régimen), pa no tener problemas, en fin, ¿qué le importan los judíos? No todo el mundo se atreve para ayudar, y no podían. Yo digo no podían hacer mucho, era tan fuerte este gobierno, inmediatamente, primero la gente no creía lo que escuchaba, pero después se acostumbraba y les daba miedo”. (Entrevista 4, 2014).

El miedo se explica por la omnipotencia del Estado para intervenir en todos los aspectos de la vida, es decir, por su universalidad, pero a la vez a por la selectividad pues la frontera que demarca al perseguido del perseguidor es muy fina y cualquier potencial adversario del régimen pasa a ser perseguido de la misma forma:

“Los mismos alemanes tenían miedo, porque si no hacían todo a la manera de Hitler los perseguían igual como perseguían a los judios, ya, años muy difíciles (...) Yo sé que cuando incendiaron esta sinagoga en Bonnheim, había un cura de Bonnheim, muy buena gente, y les decía: están destruyendo una casa de dios, ¡Por dios como pueden hacer eso! Le dijeron: si no te callas te tiramos a las llamas." (Entrevista 4, 2014).

En ese sentido el miedo es una condición que posibilita la comprensión de la obediencia tanto de la población alemana no perseguida como de la población perseguida dentro y fuera de Alemania, en los países donde también llegó el totalitarismo:

"Pasó en Alemania, en todas partes donde llegaba el nazismo, en Polonia, en Italia... Nadie, yo, no lo entiendo, como yo mucha gente que lo ha vivido no lo ha podido entender, todos tenían miedo, se vivía con miedo: nosotros con más que ellos, los alemanes también”. (Entrevista 4, 2014). 
Ahora, más específicamente para llegar a comprender la obediencia en la población perseguida es preciso considerar las condiciones en las que vivieron, que llegaron a tal límite que la prioridad era sobrevivir:

"Cuando estás metido lo único que te tiene que preocupar es que tienes que sobrevivir, que tienes dónde dormir y que tienes para comer, ese tipo de cosas, entonces uno no piensa muchas cosas (...) uno pensaba solamente hay que salir." (Entrevista 1, 2014).

\section{Las acciones/interacciones}

"Estaban conformes con el régimen si... seguramente muchos estaban convencidos que hacen bien en matar a los judios y que desaparecieran, otros se callaron y no mencionaron nada”.(Entrevista 2, 2014)

Las acciones e interacciones hacen referencia a las tácticas o rutinas que realizan los sujetos (Araujo \& Flores, 2013) y logran aquí dar una idea acerca de cómo se comportaban los sujetos en relación al régimen establecido, sin embargo aquí se da cuenta de que estas pautas de acción no son necesariamente deliberadas o realizadas en condiciones que los sujetos puedan controlar.

Al analizar el funcionamiento del Estado totalitario alemán pareciera en ciertos momentos que hubiese sido solo una gran maquinaria automatizada, sin embargo es importante considerar que para que en 12 años los nazis hayan hecho todo lo que hicieron se necesitó de la movilización de muchas personas dedicadas activamente. En ese sentido, el primer elemento que destaca es la activa promoción de la ideología nazi, que fomentaba el odio desde las instituciones educativas y los aparatos de control:

"Ya, todos los días, había, como se llamaba, Der Sturmer, aparecía una no sé, una vez a la semana, solamente contra los judios. Los otros lo hacían porque si te 
dicen tanto los judios son malos, algo, algo de verdad tiene, y los otros por miedo, les castigaban” (Entrevista 1, 2014).

Así se amedrenta al perseguido, se le quita la condición de humano, se le excluye primero socialmente (exclusión), luego físicamente (guetos y deportaciones) y finalmente hasta de manera ética, pues se les quita de su condición humana y se los envía a los campos de concentración y exterminio. Esto solo es posible desde un proceso de inserción ideológica que permita romper con la unidad previa, es necesario romper totalmente el vínculo social. Por otra parte, no se puede comprender la efectividad del Estado en esto sin una bajada a nivel más local a partir de cadenas de mando y obediencia:

"Entonces (un hombre de la SS) me dijo: Si mi Fuehrer me hubiera ordenado matar estos judios ahí, con un balazo, yo lo habría hecho porque es una orden, pero desde que yo conozco a usted nunca se le ocurría, nunca”. (Entrevista 2, 2014)

La discriminación y la violencia fueron enseñadas y practicadas desde la comunidad más cercana $^{13}$, así como desde las mismas instituciones educativas y los movimientos juveniles, todo esto permitía una desafección emotiva frente al sujeto perseguido, de manera similar a lo que Arendt (1963) denominó la "banalidad del mal":

"Me acuerdo que pregunté a una de mis amigas alemana: oiga ¿qué hacen en la Hitlerjugend? Mira, dijo, principalmente nos enseñaron, nos están enseñando a odiar a los judíos -así como la cosa más natural del mundo-. Le dije que si sabía

\footnotetext{
13 "Por ejemplo en el camino al colegio, yo caminaba 3 cuadras al colegio o 4 cuadras, nada, nos tiraron piedras los otros niños, es como si todo el mundo, era como público que uno era judio sabes, es porque había un diario también (...) en esa época que todavía podían ir juntos a clase, pero ya empezaron las niñas entre ellos a mencionar: "ahi hay un judio, ahi otro judio" y así, hasta que ya después ya no podían seguir..." (Entrevista 1, 2014)
} 
que yo soy judía... Pero claro, si eso no tiene nada que ver contigo. ¿Con quién entonces? Yo tenía 11 años. Con los otros, dicen que hay judíos muy malos. Y así educaron a la gente al antisemitismo." (Entrevista 4, 2014)

Las cadenas de mando y obediencia por otro lado también eran eficaces si pensamos en lo que se nombró anteriormente como estigmatización ${ }^{14}$, pues todo aquel que se relacionaba con los perseguidos, eso hacía que la exclusión social se diese por motivos de (in)deseabilidad social:

"Si yo convidara a alguno de los niños en mi clase, a mi cumpleaños por ejemplo, a mi mamá por ejemplo le decían: "pero mire señora Rogazinski, lo sentimos mucho pero usted comprenderá que la situación, que no se puede” (Entrevista 1, 2014).

En el caso de la población perseguida fue primando ante todo la inacción, la impotencia ante el Estado totalitario, pues todas sus estrategias de socialización, de resistencia o de escape fueron aplastadas:

"Yo me acuerdo la Estela, otra amiga judía, pero que no vivía en el vecindario inmediato, digamos, así que no nos veíamos, de vez en cuando no más. Entonces andábamos las dos en la calle, ella tenía quizás 2 años más que yo... Ah, dicen, mire, que yo estoy contaminando a los arios, refiriéndose a mi amiga, entonces mi amiga le dijo: ¡yo también soy judía! Porque teníamos eso que no nos dejábamos aplastar (...) Si, somos judíos ¿Y qué? Pero después eso es, te aplastaban igual, y

\footnotetext{
${ }^{14}$ Esta estigmatización queda reflejada en la siguiente cita: "Yo tenía muchas amigas alemanes alemanes, este Ehrmann que salvó a mi padre de la policía, que lo tenían preso, imagínese, no todos los alemanes eran malos, ni todos los nazis eran malos. (...) Y tenía muchos amigos alemanes, pero, se cortó la amistad, si no se podía, a los otros les sacaban la mugre si los pillaban con judíos." (Entrevista 3, 2014).
} 
si no tenías cuidado te mataron, si te quedabas te mataron, porque yo tenía después una lista ahí de Werner allá, de los niños judios, muchos más o menos de mi edad, que quedaron en Magdeburg y los llevaron a los campos de exterminio, con sus padres”. (Entrevista 1, 2014)

En las entrevistas se pueden identificar también ciertas prácticas de resistencia ante el régimen nazi y relaciones de solidaridad (con los perseguidos y entre ellos mismos), que a todas luces eran más bien aisladas y se volvieron cada vez más infructuosas a medida que el poder del régimen se tornaba omnipotente. Es necesario recalcar que existieron insubordinaciones, desde lo más discursivo hasta atentados directos, pero como sabemos no fue lo que primó sino la historia habría sido diferente:

"No, solidaridad con nosotros muy poca gente se atrevía, porque no te olvides, había mucha gente que espiaba y te denunciaban a las autoridades, y no se hubieran atrevido. Pero por ejemplo un doctor que vivía en el mismo edificio que nosotros, cuando vinieron en la noche a buscar al papá, a llevarlo detenido y a llevarlo después a los campos de concentración el 9 de noviembre del 38, entonces ese doctor del segundo piso, nosotros estábamos en el tercero, dijo: “miren, váyanse, aquí no hay judios”, pero ellos sabían muy bien, tenían todos los datos, he was trying to help, but that was completamente unexpected, no se podía esperar eso." (Entrevista 1, 2014).

\section{Conclusiones del estudio}

"De no usar la comprensión podría ser vista como patología, una típica forma de autosatisfacción, cuando en realidad se trata de una relación instrumental con la crueldad, de su uso al servicio de objetivos supuestamente superiores. El problema de esas afirmaciones tan rotundas en que ellas confunden comprensión 
con justificación, con aceptación moral [...] es indispensable colocarse en el mundo de vida de los actores para desenmascarar las categorías reflexivas, el tipo de moralidad que hicieron posible el genocidio judio o, en Chile, el terror de la revolución capitalista.” Moulian, 1997, pp. 348

Ha existido históricamente una dificultad para comprender el fenómeno del nazismo, el totalitarismo y la barbarie. La humanidad no alcanzó a procesar lo que estaba sucediendo y en algunos casos, durante años, se negó a aceptarla. Existen numerosos estudios sobre el periodo del nazismo, por desgracia una gran cantidad de ellos terminan por ver en el periodo nazi prácticamente una necesidad histórica o el desenlace de una historia ya escrita (Adorno \& Horkheimer, 1994). Algunos ven la barbarie nazi y el genocidio como parte de una senda errática que ya se ha corregido. ${ }^{15}$ Y otros como Habermas (1994) y Sternberger (1987) plantean la imposibilidad de la comprensión en este asunto, donde: "la venerable doctrina de la comprensión choca aquí con un muro masivo... el monstruoso y demencial crimen que designamos Auschwitz es algo que no puede en realidad entenderse” (Sternberger, 1987, pp. 733-748)

En cambio, el interés de este estudio apuesta por la comprensión de la obediencia civil, como un fenómeno que no fue aislado sino preponderante en el régimen nazi y que no puede explicarse únicamente como obediencia debida:

“Un examen históricamente riguroso de esta parte de nuestro pasado probaría rápidamente que el exterminio de millones de perseguidos indefensos se compone de innumerables decisiones y acciones criminales de singulares, y que no se puede en modo alguno señalar exclusivamente, con aquella facilonería que han hecho propia, a los superiores, en resumidas cuentas al Fuehrer mismo. Que haya

\footnotetext{
${ }^{15}$ Dentro de la pauta de entrevista se incluyeron una serie de preguntas en torno a la especificidad versus la proyección futura que ha tenido el genocidio. En esto se identificó por un lado una mirada que está ligada mayormente a una visión poco critica de lo sucedido y lo ve más bien como un hecho aislado, como que todo ya pasó pero por otro lado esta visión se liga a una victimización exclusiva del pueblo judío: "Bueno, eso después ya terminó eso así que ya no sirvió eso...Terminó la guerra y perdieron la guerra, y ya todo cambió" (Entrevista 3, 2014).
} 
podido pasar lo que ha pasado no es el resultado solamente de cualidades milagrosas del Fuehrer, sino ni más ni menos de una 'increíble obediencia'." (Mitscherlinch, A. \& M., 1970, p. 40)

La conclusión más relevante de este estudio es la convicción de que lo sucedido en Alemania, en un tiempo y un contexto dado, de ningún modo se trata de un fenómeno histórico aislado ni acabado, pero tampoco necesario. Al considerar el totalitarismo y el autoritarismo en su contingencia (Foucault, 1992), es que se plantea que debe poder ser evitable, tanto hoy como a futuro. Es por esto que se hace necesaria la educación en memoria, como una historia viva ${ }^{16}$, en tanto se entiende la conexión de "La Historia" con las más pequeñas pero no menos importantes historias personales y colectivas. Allí donde la transmisión se debilita y se da solo derivadamente (Groppo, 2002) el rescate de la memoria se hace un ejercicio necesario -tanto en Alemania como en Chile, y en toda sociedad con heridas similares- contra la construcción de justificaciones históricas $^{17}$, que impiden las transformaciones sociales aún ya finalizados los regímenes dictatoriales (Moulian, 1997).

Para finalizar, se plantea la importancia de seguir analizando estas problemáticas ${ }^{18}$, y de hacer que estos debates logren llegar a nuevos públicos para que se pase de la comprensión a la acción, así avanzar en la responsabilidad moral que nos cabe ante el destino de los otros y contra las prácticas conformistas:

\footnotetext{
${ }^{16}$ Cabe destacar la labor de transmisión invaluable que hacen los centros de memoria en Chile, sobre todo por la lucha por los Derechos Humanos en su conexión con el presente y futuro, entre otros la Casa de Memoria José Domingo Cañas, Londres 38, Villa Grimaldi y Memorial Paine.

${ }^{17}$ Representantes de esta visión se ven sobre todo en la interpretación blanqueadora de culpas que se le dio en la DDR desde el partido oficial SED, que planteaba que el régimen nazi no tuvo reales bases sociales más que los altos jerarcas y la burguesía: "En base a este acuerdo, la población germano-oriental fue transformada, retrospectivamente, en una masa de luchadores antifascistas activos en contra del Nacionalsocialismo, y así se eliminaban las culpas pasadas" (Groppo, 2002, pp. 43)

${ }^{18}$ Hay una serie de aristas que pueden ser relevantes para futuras investigaciones, pero que sin embargo este estudio no ha podido ahondar por razones prácticas. Se trata de la diferenciación entre las zonas rural /urbana, de género y la diferenciación de clase como variables relevantes para comparar las prácticas diferenciadas y el grado de inserción del nazismo. También parece relevante considerar a otros actores como las iglesias, los sindicatos y los partidos políticos que aquí no se han tematizado mayormente. Y por último, la conexión de los estudios entre sí, por ejemplo profundizando a través de estudios comparativos, a fin de generar concepciones y teorías que abarquen la sociedad como un todo dinámico y en permanente conflicto.
} 
“En cualquier situación en que otro ser humano sea negativizado, hostigado, denigrado, aislado, estigmatizado, secuestrado, torturado, aniquilado, nuestra responsabilidad moral es total y absoluta respecto a su destino. La responsabilidad de cada uno de nosotros: de los familiares, de los amigos y los conocidos, pero también la del testigo del secuestro, la del vecino, la del conocido del torturador. Una práctica social genocida no podría avanzar si pudieran darse algunos pasos hacia semejante reformulación moral.” (Feierstein, 2011, pp. 405)

\section{Bibliografía}

Adorno, Theodor W. (1969) Consignas. Trad. Ramón Bilbao. Buenos Aires: Amorrortu editores, 1973. Intervenciones. Nueve modelos de crítica. Trad. Roberto J. Vernengo. Caracas: Monte Avila Editores.

Adorno, Theodor W. y Horkheimer, Max. (1994) Dialéctica de la Ilustración. Fragmentos filosóficos. Trad. Juan José Sánchez. Madrid: Editorial Trotta.

Araujo, K., \& Flores, R. (2013). Análisis de datos cualitativos: el caso de la grounded theory. En M. Canales, Escucha de la escucha. Santiago: LOM.

Arendt, Hannah. (1998) Los orígenes del Totalitarismo. Madrid. Taurus.

Arendt, Hannah. (1963) Eichmann en Jerusalén: Un estudio sobre la banalidad del mal. Barcelona, Ed. Lumen 
Arriola, J. (2013). Ilustración y Mito: el origen de la barbarie en Adorno, Horkheimer y Cassirer. Revista de Teoría política.

Cassirer, Ernst. (2008). Filosofía de la Ilustración. México: Ed. Fondo de Cultura Económica

Cassirer, Ernst. (1946). The Myth of the State. New Haven: Yale University Press.

Cassirer, Ernst. (2001). Mito y lenguaje. Argentina: Ed. Galatea Nueva Visión.

Feierstein, Daniel. (2011). El genocidio como práctica social: entre el nazismo y la experiencia argentina. Buenos Aires: Fondo de Cultura Económica.

Foucault, M. (1992). Nietzsche, la genealogía, la historia. En M. Foucault, Microfísica del poder (pp. 7-30). Madrid: La piqueta.

Galenson, W., \& Zellner, A. (1957). International comparison of Unemployment rates. NBER.

Girard, Rene. (1982) El chivo expiatorio (cap.1). Editorial Anagrama.

Goldschmidt, Eva. (2013) Escaping Hitler. Alabama: A Jewish Haven in Chile.

Groppo, Bruno. (2002) "Memoria y olvido del pasado nazi en la Alemania de la segunda posguerra", en Memoria. Revista mensual de política y cultura, núm. 164.

Habermas, J. (1994). Identidad nacional e identidad postnacional. En J. Habermas, Identidades nacionales y postnacionales (pp. 111-121). España: Tecnos.

Larraín, J. (2001). Identidad chilena. Santiago: LOM.

Levine, J. M. y Pavelchak, M. A. (1986). Conformidad y obediencia. En S. Moscovici (ed.), Psicología. Social, Vol. 1 (pp. 41-70). Barcelona: Paidós. 
Lewy, M. (Noviembre de 2014). Entrevista 3. (A. Alvestegui, Entrevistador)

Matus, Mario (2012) El viaje inmigratorio de familias judías hacia Chile en el siglo XX. Cuadernos judaicos. 2012

Michels, U. (Octubre de 2014). Entrevista 2. (A. Alvestegui, Entrevistador)

Mitscherlinch, Alexander y Margarethe, (1970) Germania senza lutto. Psicoanalisi del postnazismo, Firenze, Sansoni.

Moulian, Tomas. (1997) Chile actual, Anatomía de un mito. Santiago: Editorial LOM-Arcis.

O'Donnell, Guilllermo. (1982) El Estado burocrático autoritario. Buenos Aires: Editorial Belgrano. 1982

Rogazinski, E. (Septiembre de 2014). Entrevista 1. (A. Alvestegui, Entrevistador)

Ruiz, J. (2009). Análisis sociológico del discurso: métodos y lógicas. Forum: Qualitative Social Research Sozialforschung, Volumen 10, №2, Mayo 2009, Artículo 26.

Schmitz, G. (Noviembre de 2014). Entrevista 4. (A. Alvestegui, Entrevistador)

Sternberger, D. (1987). Unzusammenhângende Notizen ûber geschichte. Merku 41, 737.

www.elholocausto.net. (30 de Noviembre de 2014). Obtenido de Historia virtual del holocausto: http://www.elholocausto.net/parte01/0114.htm

Weber, Max. (2005) Economía y sociedad. Esbozo de sociología comprensiva, trad. J. Medina Echavarría, ed. J. Winckelmann. México: Fondo de Cultura Económica. 